\title{
Bowel and bladder dysfunction and vesicocentricity
}

\author{
Andrew MacNeily, MD, FRCSC \\ Department of Urologic Sciences, University of British Columbia, Vancouver, BC, Canada
}

Cite as: MacNeily A. Bowel and bladder dysfunction and vesicocentricity. Can Urol Assoc J 2021;15(2):19. http://dx.doi.org/10.5489/cuaj.7101

See related guideline on page 13

$\mathrm{P}$ ediatric urologists are typically referred a large cohort of patients with a constellation of lower urinary tract symptoms. Several terms have been applied to this problem: dysfunctional voiding, dysfunctional elimination syndrome, and most recently, we've adopted bowel and bladder dysfunction (BBD). Most of these patients do not have an anatomical problem requiring surgery. Many, but not all patients have resolution of their BBD over time, with or without the various therapeutic interventions outlined in this issue's guideline by Afshar et al. ${ }^{1}$ Unfortunately, despite a meticulous analysis of the literature, the authors of the guideline are unable to provide a strong endorsement for most of the current bladder therapies we use for BBD. This is owing to the many challenges enumerated by the authors, including poor study quality and design, inconsistent terminology making pooling of data problematic, and variable methods of delivering the same treatments to a heterogeneous population. ${ }^{1}$ Aside from recommending timed voiding with an alarm watch, stool softeners, and reassurance, I feel that much of what we have tried for BBD amounts to alchemy.

Perhaps we are treating the wrong organ. Instead of being such vesicocentric urologists, maybe we should become more neurocentric in our approach to BBD. After all, we know that higher brain centers function largely to inhibit the detrusor. It seems quite likely in the emerging literature that a significant minority of BBD patients have an underlying neuropsychiatric condition contributing to their urological symptoms. Perhaps urologists (and more importantly, primary care physicians) should be routinely screening their patients with BBD for conditions such as anxiety, attention deficit, depression, and obsessive-compulsive disorder. ${ }^{2-9}$ Focusing on these diagnoses, with known effective treatments, before investigating and treat- ing the end organ might prove more beneficial for patients and less frustrating for urologists.

The guideline authors have been dealt a difficult hand to play. Nonetheless, they should be congratulated for wading through the literature on such a poorly understood and variably managed problem. I look forward to the update of this guideline in five years, when hopefully, there will be more data on neuropsychiatric interventions and their effect on BBD.

Competing interests: The author reports no competing personal or financial interests related to this work.

\section{References}

1. Afshar K, Dos Santos J, Blasi A-S, et al. Canadian Urological Association guideline for the treatment of bladder dysfunction in children. Can Urol Assoc J 2021;15(2):13-8. http://dx.doi.org/10.5489/cuaj.6975

2. Franco I. The central nervous system and its role in bowel and bladder control. Curr Urol Rep 2011;12: 153-7. https://doi.org/10.1007/s11934-010-0167-8

3. Duel BP, Steinberg-Epstein R, Hill M, et al. A survey of voiding dysfunction in children with attention deficithyperactivity disorder. J Urol 2003;170:1521-3; discussion 1523-4. https://doi.org/10.1097/01. ju.0000091219.46560.7b

4. Niemczyk J, Wagner C, von Gontard A. Incontinence in autism spectrum disorder: A systematic review. Eur Child Adolesc Psychiatry 2018;27:1523-37. https://doi.org/10.1007/s00787-017-1062-3

5. Logan BA, Correia K, McCarthy J, et al. Voiding dysfunction related to adverse childhood experiences and neuropsychiatric disorders. J Pediatr Urol 2014;10:634-8. https://doi.org/10.1016/i.jpurol.2014.06.012

6. von Gontard A, Equit M. Comorbidity of ADHD and incontinence in children. Eur Child Adolesc Psychiatry 2015;24:127-40. https://doi.org/10.1007/s00787-014-0577-0

7. Jiwanmall SA, Kattula, D. Obsessive-compulsive disorder presenting with compulsions to urinate frequently. Indian J Psychol Med 2016;38:364-5. htrps://doi.org/10.4103/0253-7176.185953

8. Rahmat R. Urinary frequency: Going beyond the tract. Malays Fam Physician 2020;15:58-60.

9. Chang K, Frankovich J, Cooperstock M, et al. Clinical evaluation of youth with pediatric acute-onset neuropsychiatric syndrome (PANS): Recommendations from the 2013 PANS Consensus Conference. J Child Adolesc Psychopharmacol 2015;25:3-13. https://doi.org/10.1089/cap.2014.0084

Correspondence: Dr. Andrew MacNeily, Department of Urologic Sciences, University of British Columbia, Vancouver, BC, Canada; amacneily@cw.bc.ca 